Gerold Prauss - Die Welt und wir 
Gerold Prauss

\title{
Die Welt und wir
}

\author{
Erster Band
}

\author{
Erster Teil : \\ Sprache - Subjekt - Zeit
}

J.B. Metzlersche Verlagsbuchhandlung
Stuttgart 
CIP-Titelaufnahme der Deutschen Bibliothek

Prauss, Gerold:

Die Welt und wir / Gerold Prauss. - Stuttgart : Metzler.

ISBN 978-3-476-00697-4

Bd. I

Teil 1, Sprache - Subjekt - Zeit. - 1990

ISBN 978-3-476-00698-1

ISBN 978-3-476-00698-1 (Band I, 1)

ISBN 978-3-476-03313-0 (eBook)

DOI 10.1007/978-3-476-03313-0

ISBN 978-3-476-00697-4 (Gesamtwerk)

Dieses Werk einschließlich aller seine Teile ist urheberrechtlich geschützt. Jede Verwertung außerhalb der engen Grenzen des Urheberrechtsgesetzes ist ohne Zustimmung des Verlages unzulässig und strafbar. Das gilt insbesondere für Vervielfältigungen, Übersetzungen, Mikroverfilmungen und die Einspeicherung und Verarbeitung in elektronischen Systemen.

(C) 1990 Springer-Verlag GmbH Deutschland

Ursprünglich erschienen bei J. B. Metzlersche Verlagsbuchhandlung und Carl Ernst Poeschel Verlag GmbH in Stuttgart 1990 


\section{Den Studenten und Studentinnen gewidmet}

die semesterlang in solcher Lehrveranstaltung geblieben sind und bleiben: an der Universität Bonn, Heidelberg, Köln, Münster und Freiburg im Breisgau.

Oberbirken, Ostern 1989

Gerold Prauss 


\section{Verehrte Leserin, verehrter Leser!}

Was Sie von diesem Buch zu einem Thema wie "Die Welt und wir" sich wohl erwarten? Schließlich haben Sie es aufgeschlagen, jedenfalls auf dieser Seite. - Sind Sie der Meinung, was die Welt und uns betreffe, sei nur Empirie mit Hilfe von Mathematik und Logik, kurz Naturwissenschaft zuständig? So darf ich Sie im folgenden verständigen, was alles daran vielmehr nichtempirisch ist. - Teilen Sie die Überzeugung, daß auch wir nicht anders denn als Naturales unter Naturalem in der Welt sind und als solches nichts als abhängig von ihm? Dann erlauben Sie mir bitte, Ihnen Gründe dafür anzuführen, daß gerade das Besondere an uns, den Menschen, als Subjekt, Bewußtsein, Absicht, Wille, Seele, Geist nichts Naturales sein kann, ja daß Naturales in der Welt gerade umgekehrt von uns als solcherart Nichtnaturalem abhängt. - Neigen Sie zu jener These, mit dergleichen wie Subjekt, Bewußtsein, Absicht, Wille, Seele, Geist wie auch mit aller Theorie darüber sei es längst vorbei, und allenfalls empirisch-stellvertretend dafür lasse über Sprache sich noch reden? So möchte ich versuchen, ob Sie durch Kritik solcher Preisgabe nicht zu manchem davon wieder Zugang finden, sprich, zur Reflexion auf sich als nichtempirischer Erkenntnis von sich selbst als Nichtempirischem. - Glauben Sie, allein Mathematik und Logik sei erfolgreich nichtempirische Erkenntnis, die Philosophie indes bloß der nach zweieinhalb Jahrtausenden jetzt endgültig mißlingende Versuch dazu? Dann darf ich Ihnen zu bedenken geben, wieviel von dieser Überlieferung als Argumentation sich halten oder gar noch weiterführen läßt, ja wieviel umgekehrt gerade Logik und Mathematik wie auch Naturwissenschaft an Philosophie erfordern. - Derlei würde Sie befremden? So lassen Sie sich vorbereiten: Ein umfassendes und angemessenes Welt- und Selbstverständnis auf der Grundlage von Argumenten können Sie aus all dem nur zusammen mit Philosophie gewinnen. Diese allerdings stellt Fragen und gibt Antworten, die das, was der alltäglichen Erfahrung und auch diesen Wissenschaften immer schon als selbstverständlich gilt, auf einmal derart fragwürdig erscheinen lassen, daß Ihnen der Kopf aus deren Sicht verrückt wird. Und so werden Sie, verehrter Leser und verehrte Leserin, beim Weiterlesen sie noch kennenlernen: Die Welt und uns. 